\title{
SIMS Imaging and 3D Microanalysis of Organic Structures
}

\author{
N. Havercroft*, D. Rading**, F. Kollmer**, E. Niehuis** \\ * ION-TOF USA Inc., 100 Red Schoolhouse Road, Building A8, Chestnut Ridge, NY 10977 \\ ** ION-TOF GmbH, Heisenbergstr. 15, Münster, 48149, Germany
}

The development of polyatomic primary ions in time-of-flight secondary ion mass spectrometry (ToF-SIMS) has opened the possibility of routinely analyzing organic samples including polymers and biological materials. This is due to the fact that cluster SIMS gives significant enhancements in molecular signal as well as the possibility to retain compositional information with depth. Imaging of cells and sub cellular features by ToF-SIMS has become possible using these sources and has the advantage that markers can be sought with no prior knowledge [1]. Depth profiling of organics was once considered a "holy grail" of the SIMS community but the polyatomic ion sources have had such a success in the field that many polymers have been successfully depth profiled. However the success of polyatomic primary ions has allowed the analysis of increasingly more complex molecules, which in turn results in difficulty interpreting the obtained spectra. G-SIMS has been demonstrated to be a useful technique for simplifying these complicated static SIMS spectra [2]. We will discuss three major areas that are leading to the developments of $3 \mathrm{D}$ analysis of organic structures.

\section{Imaging of organic materials}

Even though ToF-SIMS biological imaging has been performed for many years, traditional sources such as gallium or indium have always suffered from low molecular ion sensitivities [3]. Since the development of polyatomic primary ion sources, such as $\mathrm{Bi}_{n}{ }^{\mathrm{q}}, \mathrm{Au}_{\mathrm{n}}{ }^{+}, \mathrm{SF}_{5}{ }^{+}$and $\mathrm{C}_{60}{ }^{+}$and their increase in molecular ion sensitivities, they are now the principle choice for imaging of organic and biological materials. The liquid metal cluster ions have the advantage of a greater useful lateral resolution than the gas ion sources, while still providing the dramatic enhancement of molecular ion signals. The key features of ToF-SIMS such as the parallel mass detection, ensures that a single data acquisition leads to the determination of the localization of a large number of biological compounds on the micrometer scale. This localization can then be correlated to biological significance. Another key advantage is that no sample preparation such as coating the surface with a matrix is needed, unlike in the more established technique of MALDI.

Detailed work has previously shown that the bismuth primary ion source shows significant improvement over the gold ion source, for biological imaging [4]. This is due to the fact that the bismuth sources has a greater primary cluster ion intensity and the doubly charge bismuth species allow a useful lateral below $400 \mathrm{~nm}$ to be reached. The authors explicitly state, "Under these conditions the recourse to any sample coating, which is done at the expense of lateral resolution, is unnecessary." Thus opening up the possibility to acquire images of tissue sections at submicron spatial resolutions, with mass ranges greater than $1000 \mathrm{amu}$ within a reasonable acquisition time.

Although this limited mass range, when compared to techniques such as MALDI, is often seen as a disadvantage, the analysis of lipids by TOF-SIMS can yield a wealth of information such as the localization of xenobiotics and lipid markers from genetic diseased etc. 


\section{D depth profiling of organic materials}

In recent years the development of sputter depth profiling of organic materials has made rapid progress. In particular, the use of a high energy $\mathrm{C}_{60}$ cluster ion beam for sputtering has drawn considerable interest. However, it has also been demonstrated that a variety of organic compounds cannot be satisfactorily profiled as characteristic molecular secondary ion signals are lost under high dose cluster ion bombardment [5-6]. In a number of studies various approaches has been applied in order to overcome this problem. These approaches include sputtering at low incident angles [7], sputtering with low energy Cs ions [8], cooling or heating of the sample [9] and using alternative cluster ions sources such as massive argon clusters [10].

We have recently profiled an Irganox multilayer reference sample introduced by NPL [11] in order to investigate the influence of energy and angle of a $\mathrm{C}_{60}$ sputter beam as well as sample rotation on depth resolution and variations in sputter rate in organic depth profiling. The sample used for this study was an Irganox 3114 multilayer sample embedded in an Irganox 1010 matrix. It has been possible to obtain characteristic molecular ion signals throughout the entire profile under all sputter conditions.

The analysis of 3-dimensional organic structures once only thought of as a dream for the ToF-SIMS community it has now become a daily occurrence for a large number of research groups. As one example we will show sections of mass-resolved secondary-ion images of normal rat kidney cells prepared on a glass substrate [12]. While performing 3D analysis of the cells a lateral resolution of $350 \mathrm{~nm}$ and an axial resolution about $100 \mathrm{~nm}$ have been achieved.

References

[1] N. Tahalla, A. Brunelle, S. De La Porte, O. Laprévote, Journal of Lipid Research 2008, 49, 438454

[2] I.S. Gilmore, M.P. Seah, Appl. Surf. Sci. 2000, 161, 465.

[3] T.P. Roddy, D. M. Cannon Jr., C.A. Meserole, N. Winograd, A.G. Ewing, Anal. Chem. 2002, 74, 4011-4019

[4] D. Touboul, F. Kollmer, E. Niehuis, A. Brunelle, O. Laprévote, J. Am. Soc. Mass Spectrom. 2005, 16, 1608-1618

[5] M.S. Wagner, Surf. Interface Anal. 2004, 36, 42-52

[6] H.-G. Cramer, T. Grehl, F. Kollmer, R. Moellers, E. Niehuis, D. Rading, Appl. Surf. Sci. 2008, 255,966

[7] J. Kozole, D. Willingham, N. Winograd, Applied Surface Science 2008, 255, 1068-1070.

[8] N. Mine, B. Douhard, J. Brison and L. Houssiau, Rapid Commun. Mass Spectrom. 2007, 21, 2680-2684

[9] C. M. Mahoney, S.V. Roberson,G. Gillen, Analytical Chemistry 2004, 76, 3199-3207

[10] S. Ninomiya, K. Ichiki, H. Yamada, Y. Nakata, T. Seki, T. Aoki, J. Matsuo, Rapid Communications in Mass Spectrometry 2009, 23, 1601-1606

[11] A. G. Shard, R Foster, I. S. Gilmore, J. L. S. Lee, S. Ray, L. Yang, SIMS XVII proceedings

[12] D. Breitenstein, C.E. Rommel, R. Moellers, J. Wegener, B. Hagenhoff, Angew. Chem. Int. Ed. 2007, 46, 1-5 